\title{
Mathematical Modeling of the Consumption of Low Invasive Plastic Surgery Practices: The Case of Spain
}

\author{
E. De la Poza, ${ }^{1}$ M. S. S. Alkasadi, ${ }^{2}$ and L. Jódar ${ }^{2}$ \\ ${ }^{1}$ Departamento de Economía y Ciencias Sociales, Universitat Politècnica de València, 46022 València, Spain \\ ${ }^{2}$ Instituto Universitario de Matemática Multidisciplinar, Universitat Politècnica de València, 46022 València, Spain \\ Correspondence should be addressed to E. De la Poza; elpopla@esp.upv.es
}

Received 13 July 2013; Accepted 4 September 2013

Academic Editor: Francisco Solís Lozano

Copyright (C) 2013 E. De la Poza et al. This is an open access article distributed under the Creative Commons Attribution License, which permits unrestricted use, distribution, and reproduction in any medium, provided the original work is properly cited.

\begin{abstract}
Plastic surgery practice grows continuously among the women in Western countries due to their body image dissatisfaction, aging anxiety, and an ideal body image propagated by the media. The consumption growth is so important that plastic surgery is becoming a normal practice among women, like any other cosmetic product, with the risk of suffering psychopathology disorders in the sense that plastic surgery could be employed as an instrument to recover personal self-esteem or even happiness. Plastic surgery practice depends on economic, demographic, and social contagion factors. In this paper, a mathematical epidemiological model to forecast female plastic surgery consumption in Spain is fully constructed. Overconsumer subpopulation is predicted and simulated. Robustness of the model versus uncertain parameters is studied throughout a sensitivity analysis.
\end{abstract}

\section{Introduction}

Society pressures women continuously to be eternally young and beautiful. Not only botox or botulinum toxin and fillers (hyaluronic acid), but also others that involve low invasive procedures such as restylane, juvederm, chemical peelings, prevelle, rosacea treatments, and vampire facelift have shown a fast growth during last decades; these concern the antiaging treatments such as face wrinkle and eyelid and are nonsurgical procedures. The consumption of nonsurgical plastic procedures is not only related to psychological drivers, but also to economic factors explained by their low costs in comparison with other procedures like augmentation of breasts or butt. The fast growth of the consumption of these procedures makes these practices become affordable and not luxury, as consequence of the bandwagon [1], and therefore closely related to the economic situation measured by the Spanish unemployment rate. Furthermore, apart from the economy, people change because of emotional waves and social influences (media, mimetic behaviour, and social contagion).

Human beings could be understood as a combination of animal and spirit. When people suffer from low self-esteem levels they try to improve their wellbeing by overpracticing those activities that make them feel better. These psychological factors are one of the motivations that explain the growth of social addictions like plastic surgery.

The attractiveness of physical appearance and stereotyped female body image pressure makes procedures such as augmentation or reduction of breasts, antiaging surgeries, rejuvenation, and/or look for an ideal body pattern become natural practices as any other consumption good in Western societies $[2,3]$; for instance, gym practices combined with diet foods and drinks are usually correlated with the consumption of aesthetic surgical practices. Indeed, it is well known that a good image eases the professional promotion and social recognition [4-7].

Apart from these sociobiological factors (drivers) of plastic surgeries, we should also consider the social contagion effect propagated by marketing $[6,7]$, human herding, and mimetic behaviour [8-10].

After surgery practice a proportion of women could be dissatisfied again with their body image by comparison with other females from their neighborhood or proceeding from the media. This phenomenon produces a contagion effect of undergoing other surgical operations [8-11].

Thus, plastic surgery has become a normal good of consumption, and it is affected by the fluctuations of the economy 
as any other economic sector. It is important to distinguish between invasive and expensive procedures that follow the pattern of luxury goods [12, 13] and are mainly affordable by high-income population while surface treatments like botox fillers are accessible to wide spread population [1416]. Moreover explicitly, during expansive economic periods expensive surgical procedures become more accessible to general population due to an improvement of credit liquidity, while during economic recessions those expensive surgery treatments are almost exclusive for rich people.

However, even when these procedures are becoming regular goods of consumption of western societies when average economic behaviour applies (11\% unemployment rate, in Spain), for the particular case of Spain, deeply affected by the economic crisis ( $27 \%$ unemployment rate in 2013 ), the emergence of these products slows down.

Forecasting the growth of plastic surgery in the female population is interesting from the economic point of view as an emergent business in the western societies but is also relevant from the point of view of public health due to the potential abuse of these practices as artificial tools to enhance personal self-esteem and confidence [17].

In this paper, we construct an epidemiological discrete mathematical model to forecast the population of female consumers of nonsurgical plastic surgery in the coming years in Spain. We deal with populations more than individuals. Individual human behaviour may be erratic, but aggregated behaviour is often quite predictable [18]. The population model approach is also founded on the mimetic human behaviour [8], human herding [10], and social contagion [9].

Epidemiological mathematical models have been employed during last years to describe the propagation of several social disorders such as the consumption of substances like alcohol, cannabis, tobacco, and so forth $[19,20]$ as well as the development of habits like compulsive shopping, workaholism, bigorexia, sex addiction, and eating disorders [21-24].

The population object of study is the women population aged from 16 to 60 years old. This population is split in three subpopulations according to their level of practice of low invasive plastic surgery (LIPS) procedures. To our knowledge there is no questionnaire in the literature measuring the level of practice of LIPS consumption. The first part of the paper is devoted to the construction of such a questionnaire that will allow us to classify the collected data into subpopulations.

Thus, we distinguish between $R$ (rational consumers), $O$ (overconsumers), and $D$ (dependent consumers).

The intersubpopulations transits are modeled according to economic, demographic, and sociologic factors that will allow the construction of a system of difference equations whose solution will permit forecast of the population of consumers in the next years.

\section{Methods}

2.1. A Questionnaire Measuring the Level of Surgery Practice. Typically there are two main ways to produce questionnaires to measure the level of consumption of a good or service, questionnaires focused on the amount of activity performed [25] and others focused on the psychological dependence of the consumer [22, 26]. Hybrid questionnaires combine both parameters to produce an appropriated questionnaire [27].

In this section, we design a questionnaire for measuring the level of consumption of plastic surgery procedures. Although our questionnaire does not distinguish surgical and nonsurgical treatments, we assume that fearless women to practicing surgical treatments are also potential consumers of non-surgical practices.

In the questionnaire we include several demographic questions apart from those related to the aesthetic surgery practice, which will play an important role in the sociological study of the subpopulations.

The contents of the questionnaire are listed below.

(1) Your marital status
(a) Single.
(b) Married/Relationship.
(c) Divorced/Widowed.

(2) Age
(a) $16-20$
(b) 20-30
(c) $30-40$
(d) $40-50$
(e) $50-60$
(f) 60-70
(g) $70+$

(3) Do you have a paid activity?

(a) Yes.

(b) No.

(4) Level of income
(a) Low.
(b) Medium.
(c) High.

(5) Level of education

(a) Primary school.

(b) High school.

(c) University degree.

(6) Has any relative or close friend undergone any aesthetic surgery procedures/treatment?

(a) Yes, how many people? --

(b) No.

(7) Have you had any experiences with aesthetic surgery during last year?

(a) Yes, how many times? - -

(b) No. 
(8) If you answered YES to the previous question, would you undergo any other aesthetic surgery, if you had economic resources?
(a) Yes.
(b) No.

2.2. Data Collection and Sampling. The population of the study is composed of the Spanish women who undergo plastic surgery aged among the interval $[16,60]$.

We passed the questionnaire once, (March and April 2012) at different locations such as a private gym a private franchised gym multilocated, and a public beach of Valencia. Participants were asked to complete a questionnaire composed of 8 questions. Each question had two and/or three possible answers; questions from 1 to 5 were related to sociodemographic data while questions from 6 to 8 were related to the practice. The classification of the individuals is based on the answer of question number 7 .

(i) $R$ : defined as rational women when their score at question 7 was 0 or 1 at year $n$.

(ii) O: overconsumer women whose answer at question 7 was equal to 2 or 3 at year $n$.

(iii) $D$ : women who scored higher than 3 at question 7 are considered dependent consumers at year $n$.

Question number 6 is related to the social contagion, which will be relevant in the model construction. Question number 8 focuses on the willingness to practice plastic surgery.

Table 1 shows data collected in our sample classifying the Spanish women by subpopulations after applying stratified sampling using data from the Spanish Statistical Institute [28].

2.3. Constructing the Mathematical Model. The purpose of this section is to develop a discrete mathematical model, which allows us to forecast the Spanish women's low invasive plastic surgery procedures for the interval 2012-2018.

As it was commented in the previous section, the population object of study was divided into three categories according to their answer to question number 7 that measures their amount of consumption.

Our attention is focused on forecasting the number of rational plastic surgery consumers $(R)$, over-consumers of plastic surgery $(O)$, and those dependent $(D)$ to low invasive plastic surgery procedures.

The low invasive plastic surgery behaviour is dynamic which means that it changes over time and embraces interactions among subpopulations. For this, a mathematical model is going to be constructed to describe this dynamic system as a system of difference equations whose unknowns are the following subpopulations.

$R_{n}$ : number of rational consumers who undergo plastic surgery procedures, aged among the interval $[16,60]$ at year $n$.
TABLE 1: Data collection and Spanish population distribution for 2012

\begin{tabular}{lcc}
\hline & \multicolumn{2}{c}{2012} \\
& Sample & Spanish women by population \\
\hline$R$ & 213 & $13,730,450$ \\
$O$ & 11 & 709,084 \\
$D$ & 2 & 128,924 \\
\hline Total & 226 & $14,568,458$ \\
\hline
\end{tabular}

$O_{n}$ : number of over-consumers of plastic surgery practice aged among the interval $[16,60]$ at year $n$.

$D_{n}$ : number of dependent consumers of plastic surgery practices aged among the interval $[16,60]$ at year $n$.

The total population $(P)$ in the time $n$ is given by

$$
P(n)=R(n)+O(n)+D(n) .
$$

As at any other western developed country the Spanish birth and mortality rates are quietly balanced, which makes the total population not increase in a significant degree [28]. However, for the particular case of Spain, due to the ferocious economic crisis (actually, 27\% unemployment rate; $57 \%$ youth unemployment rate) we have exceptional emigration events. Firstly, jobless immigrants are returning to their countries of origin but also unemployed Spanish citizens are emigrating looking for a job abroad.

In particular, the impact of the crisis over the Spanish economy, 200,000 foreign immigrants are coming back to their countries yearly. In addition, about 100,000 Spanish citizens yearly leave Spain seeking for a job overseas [29]. Both facts involve a net decrease of the Spanish population of about 350,000 people per year and approximately 175,000 women. Disregarding people under 16 years old, we estimate that about 300,000 people older than 16 years old leave Spain every year since 2012 until 2018. Thus, the amount of approximately $E=150,000$ women leaves Spain yearly during the considered period of study.

The dynamic behaviour of the low invasive plastic surgery practices is based on subpopulations' transits explained by coefficients that need to be modeled according to economic, sociodemographic, and contagion hypotheses, and also collected data analysis.

The period of study started in 2012, when the first sample of the study was obtained, and finishes in 2018. People behaviour changes along the time, not only because of biology but also because of external influences (media, contagion, mimetic behaviour, human herding, and economy) and psychological drivers (low self-esteem, poor wellbeing and self-confidence). This motivates the consideration of subpopulation transits that are computed throughout sociological analysis and assuming behavioural hypotheses.

Then, the dynamics between subpopulations $R, O$, and $D$ are estimated for the interval $[n, n+1]$.

(a) The influence of an economic change could cause the transit of women between categories $R, O$, and $D$ following the economic trend. 
(b) The contagion effect based on low levels of selfesteem combined with the mimetic behaviour, social contagion, and bandwagon $[1,8-10]$ leading to the transit from $R$ to $O$ and also from $O$ to $D$ due to the contact between women who underwent LIPS procedures.

(c) We estimated from the annual survey on aesthetic procedures provided by [30] the relationship between the economic behaviour throughout the Spanish unemployment rate and women who underwent plastic surgery.

The dynamics of the model are illustrated in Figure 1 and described by the following equations:

$$
\begin{gathered}
R(n+1)=\left(1+\alpha_{b}-\frac{d_{i}+\alpha_{f}}{3}\right) R(n)-\alpha_{r} R(n) \\
\quad-\alpha_{e}(n) R(n)-\gamma_{1} R(n)-E, \\
O(n+1)=\left(1-\frac{d_{i}+\alpha_{f}}{3}\right) O(n)+\alpha_{e}(n) R(n)+\alpha_{r} R(n) \\
-\beta_{e}(n) O(n)+\gamma_{1}(R(n)-O(n)), \\
D(n+1)=\left(1-\frac{d_{i}+\alpha_{f}}{3}\right) D(n)+\beta_{e}(n) O(n)+\gamma_{1} O(n),
\end{gathered}
$$

or in the following simplified form:

$$
\begin{gathered}
R(n+1)=\left(1+\alpha_{b}-\frac{d_{i}+\alpha_{f}}{3}\right) R(n) \\
-\left(\alpha_{r}-\alpha_{e}(n)-\gamma_{1}\right) R(n)-E, \\
O(n+1)=\left(1-\frac{d_{i}+\alpha_{f}}{3}\right) O(n)+\left(\alpha_{e}(n)+\alpha_{r}\right) R(n) \\
-\beta_{e}(n) O(n)+\gamma_{1}(R(n)-O(n)), \\
D(n+1)=\left(1-\frac{d_{i}+\alpha_{f}}{3}\right) D(n)+\left(\beta_{e}(n)+\gamma_{1}\right) O(n),
\end{gathered}
$$

The values of all parameters were estimated from different sources of information and hypotheses with the exception of the transit $\alpha_{r}$ and $\gamma_{1}$ obtained from [28] and the survey designed and implemented in this study.

In the following, we describe the construction of the parameters of the model.

(i) $\alpha_{b}(n-16)$ is the birth rate of the Spanish population at year $(n-16)$. This parameter is estimated according to the data coming from [28]. We assume that all women becoming 16 years old in Spain enter into the system as rational consumers.

(ii) Then, the exit from the system could happen due to two reasons: the biological deaths measured throughout the rate of death $\left(d_{i}\right)$ of women up to 60 years old as well as those of women aging 61 years old. $\alpha_{f}$ are women who become out of our age period interval. Both coefficients are assumed to

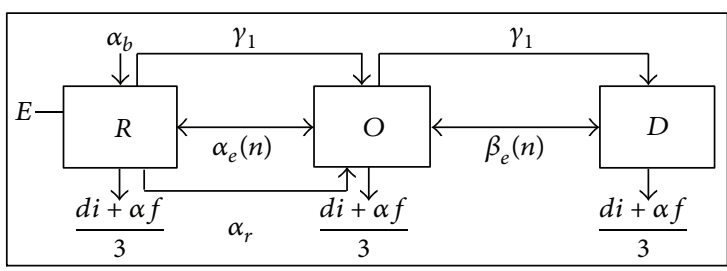

FIGURE 1: Block diagram of the system's dynamics.

remain constant for the period of study. Due to the lack of reliability of the available information, we assume that the system death probability is the same for all three categories.

(iii) $\alpha_{r}$ is the recovery rate of self-esteem. The coefficient is split into two components: $\alpha_{r 1}$ and $\alpha_{r 2}$.

(a) $\alpha_{r 1}$ : we estimated that from the rate of rational Spanish consumers of botox $(C=0.49 \%)$ [31], $8 \%$ of the rational Spanish women aged in the interval $[30,45]$ were treated with botox looking for a better physical image [32], and 1\% did it in order to overcome some emotional drawback (such as a relative passing away, a divorce, or a loss of job). We weighted $\alpha_{r 1}$ as 2/3 of $\alpha_{r}$. In general, women between the age interval $[30,45]$ are more interested in taking care of their physical appearance, which justifies the weight $2 / 3$ :

$$
\begin{aligned}
\alpha_{r 1} & =0.42 \times 0.004924787 \times(0.08+0.01) \times \frac{2}{3} \\
& =0.000124105 .
\end{aligned}
$$

(b) $\alpha_{r 2}$ : again, we estimated that from the proportion of Spanish women that underwent botox treatments $(0.49 \%)$, those who were among the age interval $[46,60]$ were treated looking for a better body image and for improving their wellbeing after suffering from emotional slowdowns; about one-third of the $35 \%$ of the divorced Spanish women underwent these plastic surgery procedures:

$$
\begin{gathered}
\alpha_{r 2}=0.32 \times 0.004924787 \times(0.35) \times \frac{1}{3} \\
=0.000183859, \\
\alpha_{r}=\alpha_{r 1}+\alpha_{r 2} .
\end{gathered}
$$

Then,

$$
\begin{aligned}
\alpha_{r} & =\alpha_{r 1}+\alpha_{r 2} \\
& =0.000124105+0.000183859 \\
& =0.000307963 .
\end{aligned}
$$

The distribution of weights, two-thirds versus one-third, between both coefficients $\alpha_{r 1}, \alpha_{r 2}$ is based on the hypothesis that in western countries like Spain, women aged in the interval $[30,45]$ used to be more concerned about their physical appearance. 
(iv) $\alpha_{e}(n)$ : the impact of the economy measured in terms of the annual Spanish unemployment rate $\delta(n)$, allowing the transit between subpopulations bidirectionally according to the economic trend as it occurs with most of consumption goods.

Observing the behaviour of both the Spanish economy the Spanish LIPS data consumption [30] and the approximated distribution of the consumers among the three categories $(R, O$, and $D)$, during the full economic crisis period 2009-2011, we suggest an approximated correlation of both variables quantified as follows.

If the unemployment rate increases by $1 \%$, the consumption of LIPS decreases by about $3 \%$. In addition, we should consider which are the transits in periods of economic recovery. However, after a long period of economic crisis in Spain, the recovery of consumption habits slows down in accordance with the economic improvement mostly for sectors such as products and services related to the body care.

We assume that if the unemployment rate $(\delta(n))$ improves by $1 \%$, the LIPS consumption recovery is $0.5 \%$ until the economic scenario achieves a stable admissible ( $11 \%$ unemployment rate) situation. This transit only affects the categories $R$ and $O$.

The coefficient is modeled as follows:

$$
\alpha_{e}(n)\left\{\begin{array}{cl}
3(\delta(n-1)-\delta(n)) C, & \delta(n)>\delta(n-1) \\
-1.5 C, & \delta(n)=\delta(n-1) \\
0.5(\delta(n-1)-\delta(n)) C, & \delta(n)<\delta(n-1)
\end{array}\right\} .
$$

The consumption of this kind of product is differently affected by the category of consumer. The dependent consumer behavior is influenced by psychological factors. Indeed, the $D$ consumer reacts differently than an $R$ or $O$ consumer to any change in the economic environment. Thus, we assume that the transit coefficient $\beta_{e}(n)$ is as follows:

$$
\beta_{e}(n)\left\{\begin{array}{cl}
4(\delta(n-1)-\delta(n)) C, & \delta(n)>\delta(n-1) \\
-2 C, & \delta(n)=\delta(n-1) \\
2(\delta(n-1)-\delta(n)) C, & \delta(n)<\delta(n-1)
\end{array}\right\} .
$$

In the present economic context of crisis, when Spanish unemployment rate is higher than $20 \%$, the propagation of the consumption of LIPS only affects the segment of women with secured incomes or wealthy people. According to our survey, women interact on a daily bases with 30 other females, from those, 1 belongs to the category $O$ or $D(3.3 \%)[9,10,33]$. This fact suggests a contagion rate of $\gamma_{1}=0.033 \mathrm{C}$. We assume that this parameter is constant all the time, but also this is a continuous jump contagion; people only jump from one category to the next level of consumption $(R \rightarrow O ; O \rightarrow D)$.

(v) $E=150,000$ is the constant approximated value of women that leave Spain looking for a job abroad due to the economic crisis. We assume that all of them are rational potential consumers of plastic surgery procedures.

\section{Results and Simulations}

The mathematical model allows us to predict the subpopulations $R(n), O(n)$, and $D(n)$ at any year $n$, in the study interval $[2012,2018]$. In order to compute the subpopulations it was
TABLE 2: Economic forecast of the annual Spanish unemployment rate expressed in percentage.

\begin{tabular}{lcc}
\hline & Pessimistic & Optimistic \\
\hline 2011 & 21.6 & 21.7 \\
2012 & 25.0 & 25.1 \\
2013 & 26.9 & 27.0 \\
2014 & 28.1 & 26.0 \\
2015 & 30.0 & $\mathbf{2 4 . 7}$ \\
2016 & 29.0 & $\mathbf{2 3 . 2}$ \\
2017 & 28.5 & 21.7 \\
2018 & 28.0 & $\mathbf{2 0 . 1}$ \\
\hline
\end{tabular}

Bold: forecasts provided by institutions (OECD, Societé Générale, IMF). Italic: own forecasts.

necessary to estimate the coefficients of the system for the next years according to two economic scenarios, one more optimistic and another one more pessimistic, reflecting the Spanish economic trend.

Thus, we based our pessimistic scenario on the economic forecast of the Spanish unemployment rate according to the Organization of Economic Cooperation and Development [34] for the years 2011 and 2014 and for the optimistic scenario the International Monetary Fund for the period [2011,2018] [35]. For 2015 we applied the rate of unemployment predicted by Societé Générale [36] for the pessimistic scenario, while we forecasted by ourselves the economic trend for the period [2016, 2018] (see Table 2).

Since organizations only forecast the Spanish unemployment rate until 2015 (Societé Générale, 30\%), we continue the predictions of the Spanish economic scenario following the $O E C D /$ Societé Générale forecast with a more pessimistic scenario while the IMF one agrees with a more optimistic approach.

Once the economic scenarios were built, we estimated the annual value of each subpopulation $R(n), O(n)$, and $D(n)$. Table 3 collects the results performed by the computation of the system expressed in absolute terms (number of women at each subpopulation at year $n$ ).

Even when the consumption of these products shows a growing trend due to the hard Spanish economic crisis, the level of activity of these services slows down between the middle class. Figure 2 illustrates this fact.

Then, we performed a sensitivity analysis of both models (pessimistic and optimistic) versus the contagious parameter $C$, involved in the coefficient $\gamma_{1}=0.033 C$. Results showed the same effect for both economic scenarios. In fact, regarding a variation interval for $C$ ranging in the interval $[0.0049,0.1]$, where the extreme value 0.0049 corresponds to the current consumption rate of LIPS procedures by Spanish women whereas the highest value 0.1 would correspond to a situation where middle class sums up to the imitation effect and the consumption of this type of goods. Figure 3 illustrates how the subpopulations vary continuously with the contagion parameter measured in terms of $C$ with robustness. 
TABLE 3: Subpopulation forecast in number of women who practice LIPS by economic scenarios.

\begin{tabular}{|c|c|c|c|c|c|c|}
\hline & \multicolumn{3}{|c|}{ Pessimistic } & \multicolumn{3}{|c|}{ Optimistic } \\
\hline & $R$ & $O$ & $D$ & $R$ & $O$ & $D$ \\
\hline 2011 & $13,778,952$ & 711,589 & 129,379 & $13,778,952$ & 711,589 & 129,379 \\
\hline 2012 & $13,669,723$ & 707,090 & 128,118 & $13,669,743$ & 707,071 & 128,211 \\
\hline 2013 & $13,558,991$ & 705,473 & 127,079 & $13,559,067$ & 705,403 & 127,261 \\
\hline 2014 & $13,444,811$ & 705,099 & 126,139 & $13,442,149$ & 707,531 & 126,651 \\
\hline 2015 & $13,336,065$ & 703,400 & 125,109 & $13,329,129$ & 709,665 & 126,067 \\
\hline 2016 & $13,227,621$ & 705,431 & 124,418 & $13,220,562$ & 711,780 & 125,500 \\
\hline 2017 & $13,120,360$ & 707,266 & 123,697 & $13,112,952$ & 713,827 & 124,938 \\
\hline 2018 & $13,014,809$ & 709,038 & 122,980 & $13,007,344$ & 715,578 & 124,317 \\
\hline
\end{tabular}

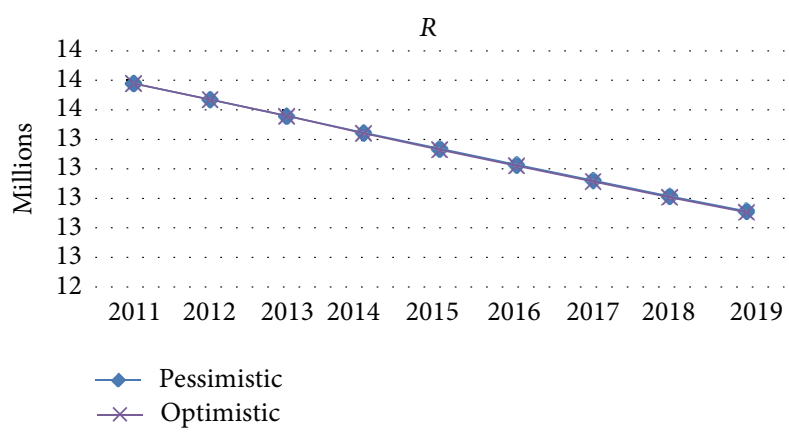

(a)

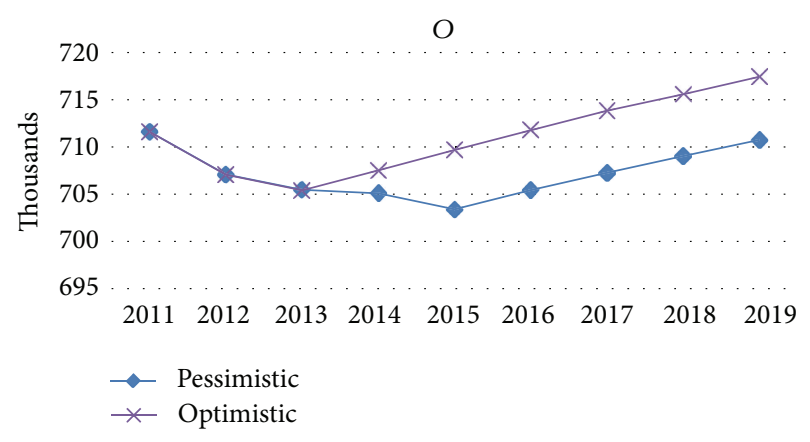

(b)

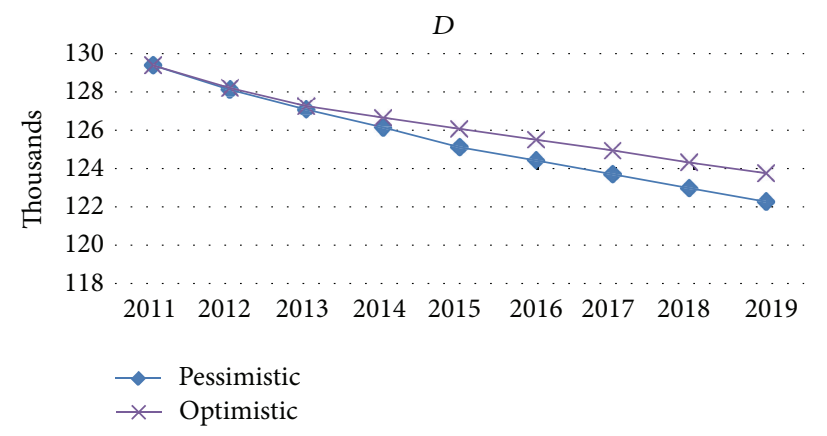

(c)

FIgURE 2: Simulated subpopulations $R, O$, and $D$ during the period 2011-2018 by economic scenario.

\section{Conclusions}

In this paper, a complete mathematical model for predicting the low invasive consumption of plastic surgery practices in Spain during the period 2012-2018 has been constructed.

To our knowledge, this is the first time the consumption of these services has been modeled from a behavioral perspective, although some statistics about the level of consumption may be found in the literature. However, previous studies focused on the willingness to consume LIPS rather than forecasting real consumption of LIPS. As consequences, our results are conservative, since we predict LIPS activity; we are taking into account economic environment, individual contagion, and emotional drives.

The LIPS consumption improves the possible professional success and the wellbeing of the person, improving her body image and social skills. However, it is important to point out that an overconsumption of these treatments can lead the person to develop disorders of dependence and identification of happiness by care of the body.

Thus, from the point of view of business and marketing it is interesting to study the propagation of these services while from the public health point of view it is interesting to study the evolution of the over-consumers and addicts.

Our discrete mathematical model is of epidemiological nature, where consumers are classified by subpopulations in accordance with a survey designed by the authors in this paper.

The study of the consumption of this product in Spain is particularly interesting due to the emergence of its consumption by middle classes in western countries as any other service employed to body care during the last decade. 


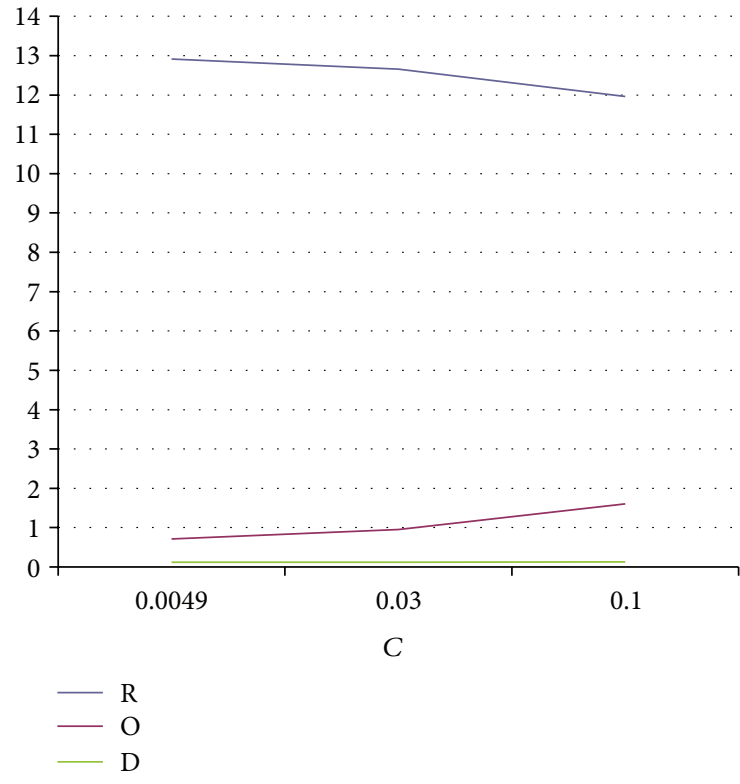

FIGURE 3: Sensitivity analysis of subpopulations (expressed in millions) versus the contagion parameter for the optimistic scenario. (Abscises represents values of the parameter C.)

However, the impact of the ferocious Spanish economic crisis slowed down its trend suddenly until the point where these services are just affordable by high-income women.

The model allows the possibility of simulating artificial scenarios simply by changing the values of the parameters and computing the subpopulations with the model. Furthermore, the model is applicable to any other region where economic and sociologic data are available.

In addition, the model has the potential advantage that the period of study can be modified assuming a loss of accuracy due to the uncertainty of the economic future.

\section{Conflict of Interests}

The authors declare that there is no conflict of interests regarding the publication of this paper.

\section{Acknowledgments}

The authors would like to thank the European Union since this paper has been financed throughout the Project FP7PEOPLE-2012-ITN Grant Agreement no. 304617 (FP7 Marie Curie Action, Project Multi-ITN STRIKE-Novel Methods in Computational Finance). The authors also thank the Hadhramout University of Sciences and Technology of Yemen for financing the Ph.d. grant for M. S. S. Alkasadi.

\section{References}

[1] M. N. Kastanakis and G. Balabanis, "Between the mass and the class: antecedents of the "bandwagon" luxury consumption behavior," Journal of Business Research, vol. 65, no. 10, pp. 13991407, 2012.
[2] M. H. Smirnova, "A will to youth: the women's anti-aging elixir," Social Science \& Medicine, vol. 75, no. 7, pp. 1236-1243, 2012.

[3] B. Garnham, "Designing "older" rather than denying ageing: problematizing anti-ageing discourse in relation to cosmetic surgery undertaken by older people," Journal of Aging Studies, vol. 27, no. 1, pp. 38-46, 2013.

[4] V. Swami, A. Arteche, T. Chamorro-Premuzic et al., "Looking good: factors affecting the likelihood of having cosmetic surgery," European Journal of Plastic Surgery, vol. 30, no. 5, pp. 211-218, 2008.

[5] V. Swami, R. Taylor, and C. Carvalho, "Acceptance of cosmetic surgery and celebrity worship: evidence of associations among female undergraduates," Personality and Individual Differences, vol. 47, no. 8, pp. 869-872, 2009.

[6] C. N. Markey and P. M. Markey, "A correlational and experimental examination of reality television viewing and interest in cosmetic surgery," Body Image, vol. 7, no. 2, pp. 165-171, 2010.

[7] J. Maltby and L. Day, "Celebrity worship and incidence of elective cosmetic surgery: evidence of a link among young adults," Journal of Adolescent Health, vol. 49, no. 5, pp. 483-489, 2011.

[8] R. Girard, Mimesis and Theory: Essays on Literature and Criticism, 1953-2005, Stanford University Press, 2008.

[9] N. A. Christakis and J. H. Fowler, Connected: The Surprising Power of Our Social Networks and How they Shape Our Lives, Back Bay Books, Little Brown and Company, Boston, Mass, USA, 2009.

[10] R. M. Raafat, N. Chater, and C. Frith, "Herding in humans," Trends in Cognitive Sciences, vol. 13, no. 10, pp. 420-428, 2009.

[11] J. Slevec and M. Tiggemann, "Attitudes toward cosmetic surgery in middle-aged women: body image, aging anxiety, and the media," Psychology of Women Quarterly, vol. 34, no. 1, pp. 65-74, 2010.

[12] L. L. Devgan and R. T. Grant, "Is plastic surgery a luxury good? An economic analysis of income elasticity of demand for commonly performed plastic surgery procedures," Journal of Plastic and Reconstructive Surgery, vol. 126, pp. 117-118, 2010.

[13] W. D. Hoyer and N. E. Stokburger-Sauer, "The role of aesthetic taste in consumer behavior," Journal of the Academy of Marketing Science, vol. 40, no. 1, pp. 167-180, 2012.

[14] G. C. Singh, M. C. Hankins, A. Dulku, and M. B. H. Kelly, "Psychosocial aspects of botox in aesthetic surgery," Aesthetic Plastic Surgery, vol. 30, no. 1, pp. 71-76, 2006.

[15] Plastic Surgery Research.info, USA, 2010, http://www.cosmeticplasticsurgerystatistics.com/statistics.html/.

[16] The British Association of Aesthetic Plastic Surgeons, UK, 2013, http://www.baaps.org.uk/about-us/press-releases/1558-britons-raise-a-few-eyebrows/.

[17] M. S. de Aquino, A. Haddad, and L. M. Ferreira, "Assessment of quality of life in patients who underwent minimally invasive cosmetic procedures," Journal of Aesthetic Plastic Surgery, vol. 37, no. 3, pp. 497-503, 2013.

[18] C. R. MacCluer, Industrial Mathematics: Modeling in Industry, Science, and Government, Prentice Hall, Upper Saddle River, NJ, USA, 2000.

[19] F. J. Santonja, E. Sánchez, M. Rubio, and J. L. Morera, "Alcohol consumption in Spain and its economic cost: a mathematical modeling approach," Mathematical and Computer Modelling, vol. 52, no. 7-8, pp. 999-1003, 2010.

[20] F. Guerrero, F. J. Santonja, and R. J. Villanueva, "Solving a model for the evolution of smoking habit in Spain with homotopy 
analysis method," Nonlinear Analysis: Real World Applications, vol. 14, no. 1, pp. 549-558, 2013.

[21] I. García, L. Jódar, P. Merello, and F. J. Santonja, "A discrete mathematical model for addictive buying: predicting the affected population evolution," Mathematical and Computer Modelling, vol. 54, no. 7-8, pp. 1634-1637, 2011.

[22] E. de la Poza, M. del Líbanob, I. García, L. J. García, and P. Merello, "Predicting workaholism in Spain: a discrete mathematical model," International Journal of Computer Mathematics, 2013.

[23] J. I. Baile, Vigorexia, Cómo Reconocerla y Evitarla, Editorial Sintesis, Madrid, Spain, 2005.

[24] F. J. Santonja, R. J. Villanueva, L. Jódar, and G. GonzalezParra, "Mathematical modelling of social obesity epidemic in the region of Valencia, Spain," Mathematical and Computer Modelling of Dynamical Systems, vol. 16, no. 1, pp. 23-34, 2010.

[25] T. F. Heatherton, L. T. Kozlowski, R. C. Frecker, and K. O. Fagerstrom, "The Fagerstrom test for nicotine dependence: a revision of the Fagerstrom Tolerance Questionnaire," British Journal of Addiction, vol. 86, no. 9, pp. 1119-1127, 1991.

[26] I. García, "La compra compulsiva: ¿impulso irresistible o reflejo del sistema de valores personales?" Revista de Psicología Social, vol. 22, no. 2, pp. 125-136, 2007.

[27] H. G. Pope Jr., K. A. Phillips, and R. Olivardia, the Adonis Complex: The Secret Crisis of Male Body Obsession, Free Press, New York, NY, USA, 2000.

[28] Spanish Statistics Institute (INE), http://www.ine.es/.

[29] E. Sánchez Torres, Spain, 2013, http://cincodias.com/cincodias/ 2013/05/22/economia/1369236470_554844.html.

[30] International Society of Aesthetic Plastic Surgery (ISAPS), USA, 2013, http://www.isaps.org/isaps-global-statistics-2012 .html.

[31] R. Ruiz Rodríguez, El Libro del Bótox, La esferae de los libros, Madrid, Spain, 2009.

[32] N. Etcoff, S. Orbach, J. Scott, and H. D. Agostino, "Más allá de los estereotipos: en reconstrucción de los cimientos sobre las creencias acerca de la belleza," Fundación Dove para la Autoestima, 2006, http://drupal.upsa.es/sites/default/files/ Informe\%20Dove.pdf.

[33] L. E. Park, R. M. Calogero, M. J. Harwin, and A. M. DiRaddo, "Predicting interest in cosmetic surgery: Interactive effects of appearance-based rejection sensitivity and negative appearance comments," Journal of Body Image, vol. 6, no. 3, pp. 186-193, 2009.

[34] The Organization for Economic Co-operation and Development (OECD), France, 2013, http://www.oecd.org/eco/outlook/ spaineconomicforecastsummary.htm.

[35] International Monetary Fund (IMF), USA, 2013, http://www .imf.org/external/pubs/ft/scr/2013/cr1354.pdf.

[36] Cross Asset Research, Sociéte Générale (SG), France, 2013, https://publication.sgresearch.com/en/3/0/172963/125179.html ?sid=5b4256d8671034005116a674000337f9. 


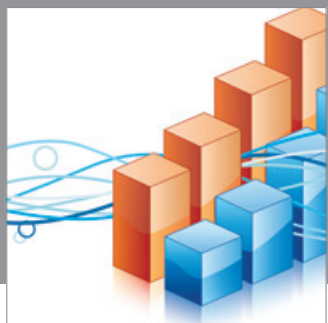

Advances in

Operations Research

mansans

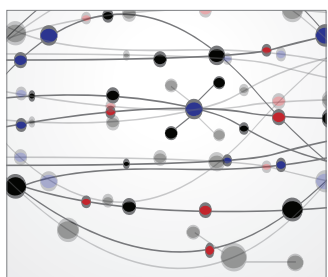

The Scientific World Journal
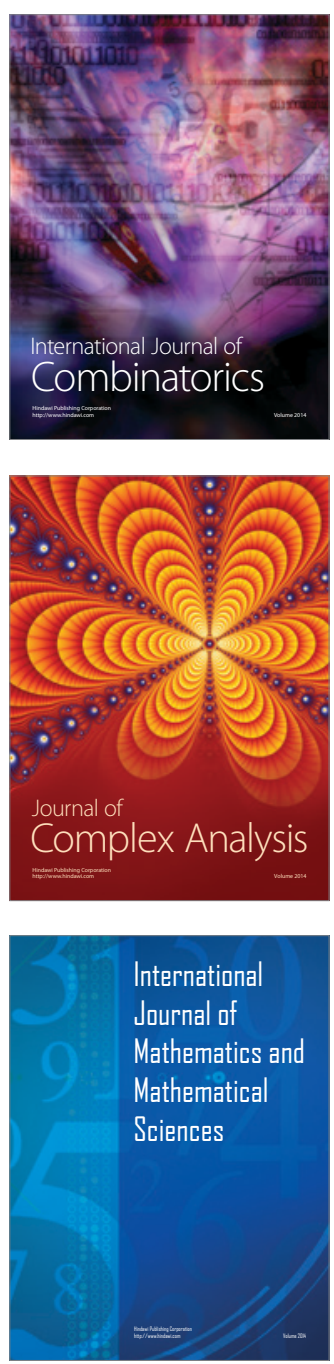
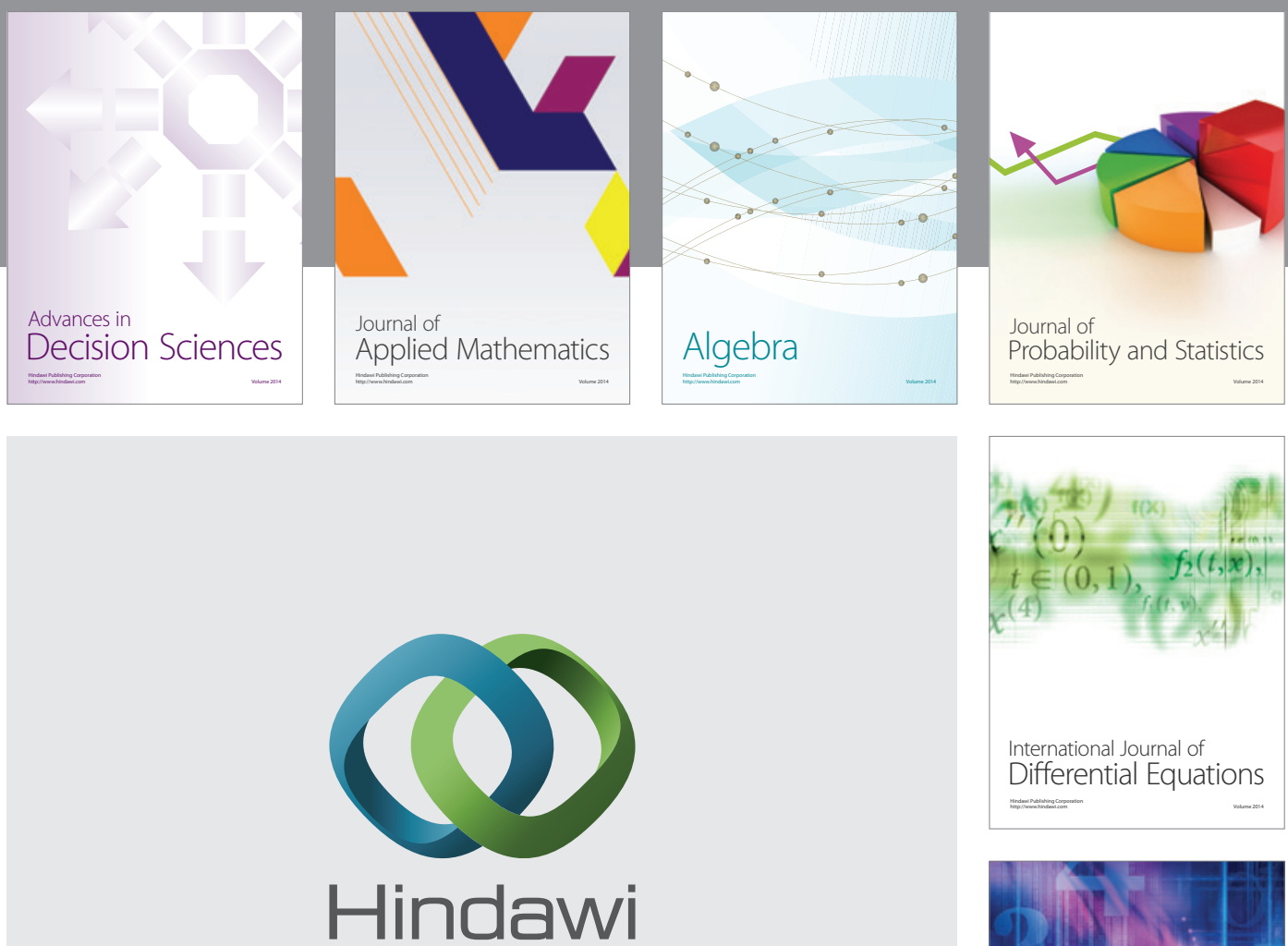

Submit your manuscripts at http://www.hindawi.com
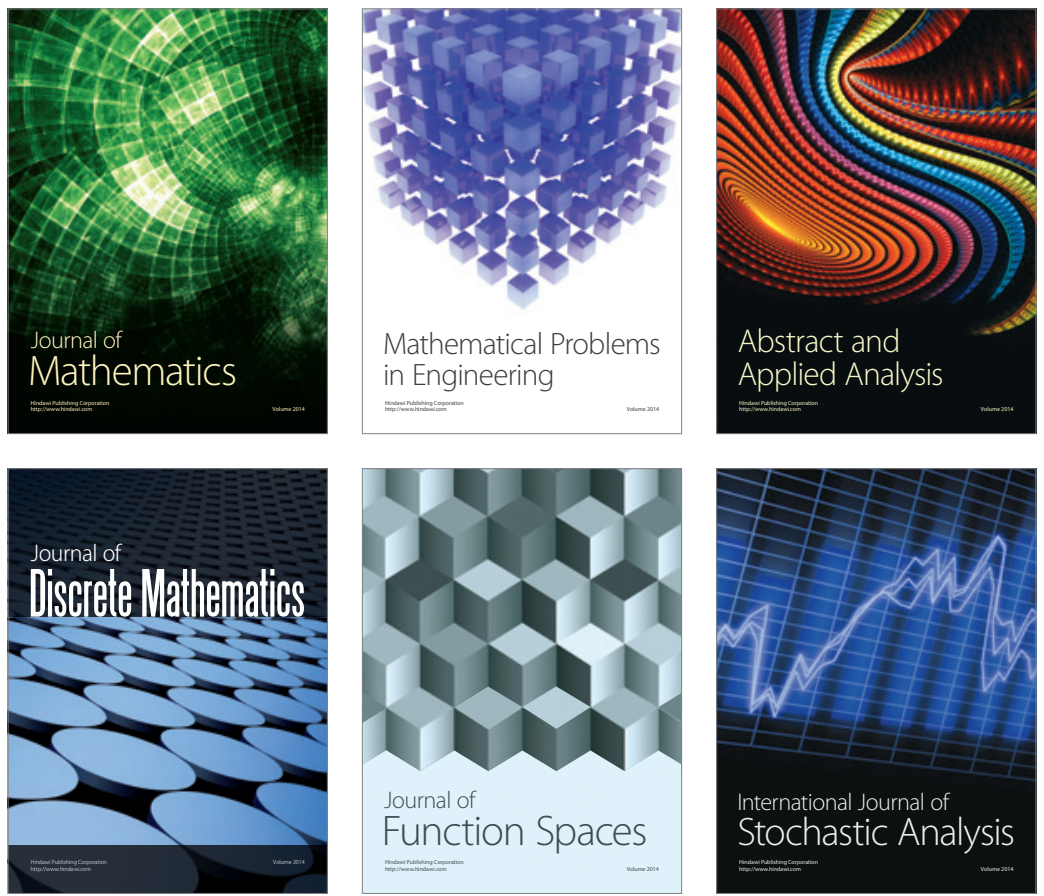

Journal of

Function Spaces

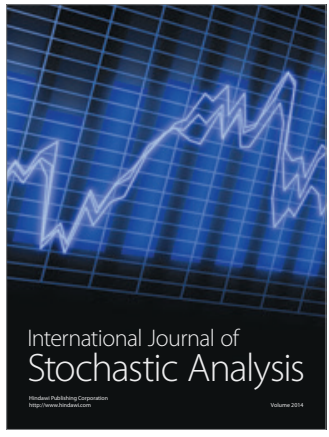

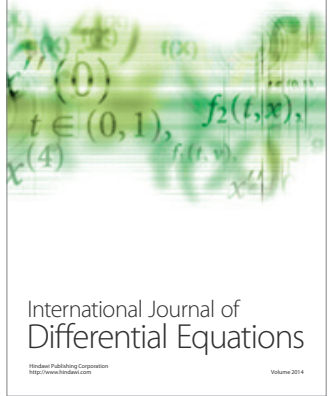
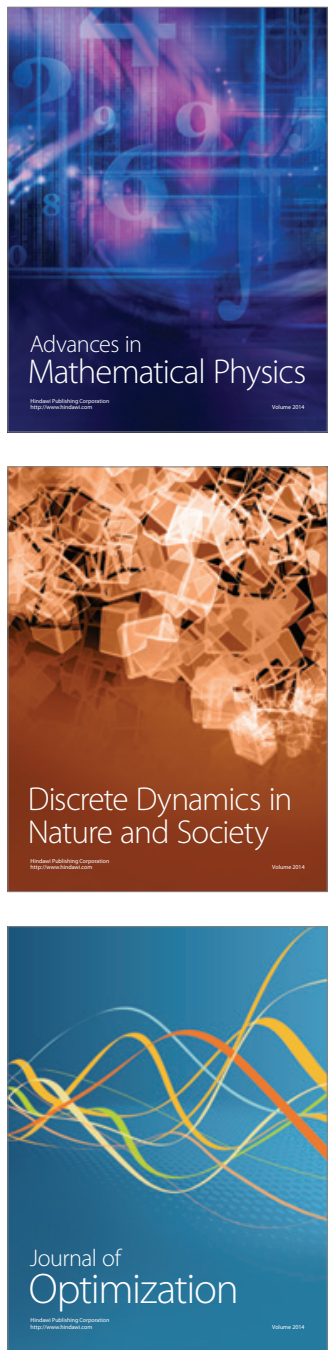